Vol: 03, Pg:30-49, Yr:2022

\title{
Carbon Dioxide Capture- A Challengefor Green Economy.
}

\author{
Soma Roy ${ }^{1 *}$, Sudipto Roy ${ }^{2}$ \\ ${ }^{1}$ Department of Biotechnology, Ranchi Women's College, Ranchi University \\ ${ }^{2}$ Department of Laboratory Medicine, Rajendra Institute of Medical Sciences, Ranchi \\ *Corresponding: drsomaroy9@gmail.com
}

\begin{abstract}
:
Carbon is a compound of multi-fold enactment. The increased carbon dioxide emissions due to various anthropogenic activities have, in turn, posed various threats and challenges to our environment. Accordingly, an innovative approach linked to themanagement strategies of carbon dioxide is the ardent need of the hour. The literature indicates that carbon dioxide capture and utilization (CCU), is an innovative concept to convert greenhouse gas into a valuable feedstock, and has been gaining much attention in the past few decades. The incremental stratospheric carbon dioxide emission due to various human activities like fossil fuel combustion, improved urbanization, etc. has, in turn, led us towards the search for more sustainable and economic routes of synthesis. With regard to this, instead of developing new strategies for the synthesis of the chemical catalysts, more nature inclined technologies and methodologies
\end{abstract} should be adopted towards creating a sustainable and clean approach. Over previous centuries, nature has designed and evolved sophisticated mechanisms for carbon concentration, fixation, and utilization manifested through autotrophy. Many photosynthetic and chemolithoautotrophic organisms, display excellent ability towards the assimilation of $\mathrm{CO}_{2}$ and subsequently followed by the conversion into complex molecules. By adopting various modern and sophisticated technologies like genetic engineering and protein engineering, the spectrum of $\mathrm{CO}_{2}$ derived bio-based products has been expanding at an alarming rate. A wide spectrum of chemicals can be synthesized biologically like bio-plastics, bio-alcohols, biodiesel,to name a few. Accordingly, continuous research on multiple nichesalong with strong collaboration and synchronizationamong scientists and engineers are required to further develop biological systems into viable chemical 
production platforms.Thus, the present study aims to explore various opportunities and their associated challenges to be applied for biological systems related to CCU.

Key Words-Carbon capture and utilization (CCU); Carbon dioxide;Protein engineering; Stratospheric Carbon reserve

\section{Introduction}

Carbon capture and utilization (CCU),indicates a concrete approachtowards the goal of the sustainable chemical industry, along with the concomitantreduction in $\mathrm{CO}_{2}$ emission into the stratospheric level of the atmosphere. Driven by the various policies as per different National and International bodies, the commitment towards reducing the carbon footprint, many innovative and novel $\mathrm{CCU}$ technologies toconvert $\mathrm{CO}_{2}$ into fuels or value-added chemicals have been adopted[1]. The chemical reactions involving $\mathrm{CO}_{2}$ are utilized by the useof appropriate catalysts, a few of which are inspired by biologicalsystems. The usage of the physicochemical approaches in CCU has beencomprehensively reported in existing literature[2].Despite various advancements which have been incorporatedtowards the utilizing of $\mathrm{CO}_{2}$ as a chemicalfeedstock, large-volume $\mathrm{CO}_{2}$ conversion still requires significant research attention. Few notable instances regarding the industrial utilization of stratospheric $\mathrm{CO}_{2}$ as per previous literature reports include the production of urea $(\sim 70$ $\mathrm{Mt} \mathrm{CO}_{2}$ per year) methanol ( $6 \mathrm{Mt} \mathrm{CO}_{2}$ per year), salicylic acid ( $20 \mathrm{kt} \mathrm{CO}_{2}$ per year), and propylene carbonate (a few kt $\mathrm{CO} 2$ per year) [3]. In contrast to that, it has been reported that on average, the photosynthetic organisms annually transmute around $100 \mathrm{Gt}$ of stratospheric carbon into respective biomass[4]. In context to that, it can be corroborated that Nature has evolvedhighly sophisticated mechanisms for carbon fixation and utilization;a resource that has remains largely untapped and unexplored which in turn could potentially be adisruptive technology in CCU.The increased carbon dioxide emissions due to various anthropogenic activities have in turn resulted in increased global warming and accordingly have received momentous research attention in the past few decades $[5,6]$.Although a wide spectrum of $\mathrm{CO}_{2}$ capture and storage platforms have been proposed,the utilization of captured $\mathrm{CO}_{2}$ from industrial plants is a progressively prevalent strategy due toconcerns regarding the safety of terrestrial and aquatic $\quad \mathrm{CO}_{2} \quad$ storage.Another remarkablestrategyinvolves the bioelectrochemical techniques through which 
electricity can be used as a potential energy source forthe microbial catalytic production of fuels and other organic products from $\mathrm{CO}_{2}$. As per previously reported studies, this approach has been widely explored as a potential technique to reduce $\mathrm{CO}_{2}$ emissions. Additionally, such approaches have also been reported to generate a wide spectrum of value-added products[7]. Accordingly, the aim of the present review was framed towards the exploration of both the possible routes of the utilization of $\mathrm{CO}_{2}$ by adopting biological as well as bio-electrochemical utilization. Within the past, a robust increase in $\mathrm{CO}_{2}$ emission has been reported in various countries like India and China $[8,9]$. The literature also indicated that around $80 \%$ of the total global energy requirement is met by fossil fuels which in turn contributes towards a major chunk (more than $60 \%$ ) of global GHG emission [10]. It has been reported that the utilization of fossil fuels generates around $3 \times 10^{16} \mathrm{~g}$ of $\mathrm{CO}_{2}$ annually[11].Moreover, the traditional wastewater treatment, along with the degradation of the organic contaminants, alsoresults in the emission of huge quantities of $\mathrm{CO}_{2}$ emissions into the atmosphere, which is expected to rise as high as $1.21 \times 104$ td $^{-1}$ by 2025 [12].

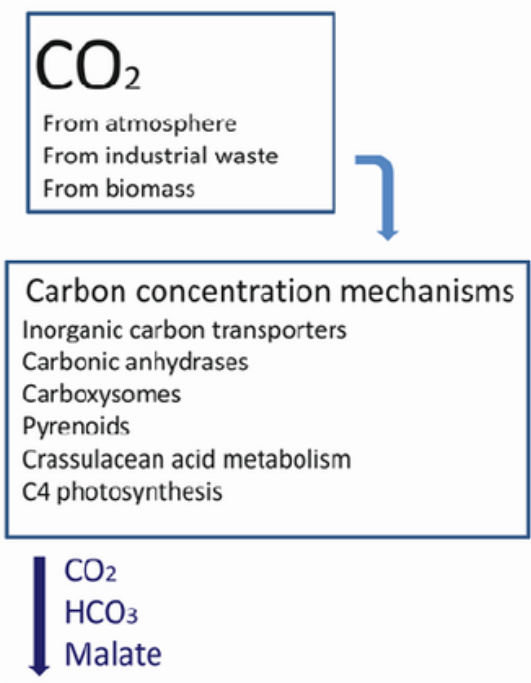

Carbon fixation pathways

Calvin-Benson Bassham Cycle Reductive Tricarbocylic acid cycle Wood-Ljungdahl pathway

3-hydroxypropionate-4-hydroxybutyrate cycle

Decarboxylate-4-hydroxybutyrate cycle

3-hydroxypropionate bicycle

\begin{tabular}{|l|}
\hline Bio-based prodcuts \\
(major) \\
Bio-plastics \\
Bio-alcohols \\
Bio-diesel \\
Lubricants \\
proteins \\
\hline
\end{tabular}

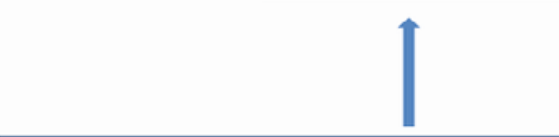

Carbon utilization (major pathways)

Central carbon metabolism

Fatty acid synthesis

B-oxidation

Glyoxylate cycle

Branched chain amino acid biosynthesis

Acetyl-CoA

Succinyl-CoA

Pyruvate 
Figure 1.Schematic representation of the carbon concentrating mechanisms, Carbon fixation pathways, and utilization techniques by the autotrophic organism, leading to bio-based products.

\section{The spectrum of microorganisms capable of utilizing $\mathrm{CO}_{2}$}

The mechanism of $\mathrm{CO}_{2}$ assimilation has not only been restricted only towards the photosynthetic organisms (like algae, plants, cyanobacteria, etc.) however as per previous literature reports, such mechanism has also been noted to be involved various autotrophic bacteria and in turn, has received significant research attention [13].Thus, in this section, an attempt has been made to summarize, the microorganisms which are mostly harnessed and accordingly could potentially be scaled up into industrialscale bioprocess. Few of those microorganisms have already been discussed in the carbon fixation pathway as detailed in Figure 1 along with their possible advantages and disadvantages to be harnessed in the biological CCU. However, this spectrum of microorganisms has not been evolved naturally to be suited for industrial-scale production of the desired products since most of their inherent properties (like growth characteristics, types of metabolites produced, thermostability, and tolerance to inhibitors to name a few) does not suit for such approaches. However, the incorporation of genetic engineering has improved the feasibility to be applied to industrial applications by phenotype improvement for expanding the repertoire of chemical synthesis. Accordingly, an attempt has been made to summarize the recent developments in this particular field of engineering these microorganisms for CCU.

\subsection{Algae}

Algae is considered as one of the major and significant agentsfor photosynthesis and carbon fixation in context to the industrial application[14]. It has also been reported that algae are more diverse and are widely found in various forms including the larger-sizedmacro-algae which are the most commonly studied along with smaller-sized microalgae[15].Furthermore, the microalgal species can further be subdivided as per structures and habitats into various classes including green algae, diatoms, red algae, yellow-green algae, golden algae, brown algae, and euglenoids[16]. Moreover, it has been reported that algae exhibit prominent photosynthetic 
organisms [17].The literature suggested that algae canutilize $\mathrm{CO}_{2}$ through the Calvin-Benson-Bassham (CBB) cycle, by converting the inorganic carbon into complex organic compounds. The key enzyme involved in the $\mathrm{CBB}$ cycle is ribulose

1,5-bisphosphate carboxylase/oxygenase (RuBisCO), which catalyzes the carboxylation of ribulose1,5bisphosphate to give two molecules of 3phosphoglycerate (3PG)[18].Out of the two molecules thus formed, 3PG is channeled into central metabolicpathways, while the other is utilized in the continuation of the cycle.However, RuBisCO has been reported to have less catalytic efficiency[19]. In addition to that, RuBisCO has also been reported to bind with oxygen due to the presence of oxygenase activity which in turn leads to photorespiration and generation of unwanted products and accordingly are linked to various drawbacks linked with the $\mathrm{O}_{2}$ and $\mathrm{CO}_{2}$ concentration in the atmosphere[20].To overcome these complications, algae have undergone various mechanisms linked to carbon dioxide concentrating mechanisms (or CCMs). The literature indicated that there are three major constituents of a CCM;1) active bicarbonate $\left(\mathrm{HCO}^{3-}\right)$ uptake transporters, 2) a suite of carbonic anhydrases(CAs) localized strategically within the cells, and 3) a subcellularmicro- compartment within which most RuBisCO is located within thepyrenoids of the chloroplasts [21].The domain of algal transgenics has received significant research cognizance in the past few years[22]. The finest available tools of genetic engineering have been harnessed to develop various model organisms like the green algaeChlamydomonas reinhardtii and Volvox carteri and the diatomPhaeodactylum tricornutum. Furthermore, the use nuclear transformation has also been adopted for many types of algae, including the industrially-relevant speciessuch as the green micro-algae Dunaliella salina and Haematococcuspluvali[23]. Various strategies have also been developed and thereby adopted for the modification of various green algae [24]. The literature reported that RNA silencing has been adopted to down-regulatethe entire gene family which encodes for light-harvesting antennacomplexes of C. Reinhardtii[25]. The obtained results indicated that the engineered alga exhibited anenhanced efficiency of cell cultivation under elevated light conditions. It was also noted that upon the application of various modern and sophisticated techniques, the green alga $C$. reinhardtiiwas reported to expresscomplex mammalian proteins in the chloroplasts, including a fulllengthIgG-1 human monoclonal 
antibody[26].A recent report has comprehensivelyreviewed the current state of this field of research and its potentialfuture applications[27].

\subsection{Cyanobacteria}

Photosynthetic prokaryotes can primarily be categorized under five major phyla namely cyanobacteria,proteobacteria, chlorobi, chloroflexi and firmicutes. The literature indicated that cyanobacteria are also referred to as micro-algal species [28]. However, unlike algae, cyanobacteria are prokaryotic in origin and possess their photosynthetic pigment within the cytoplasm rather than specializedorganelles as compared to eukaryotic plants and algae. These organisms also have been reported to fix atmospheric nitrogen by using nitrogenase as well as inorganic carbon. The literature also suggested that cyanobacteria are believed to play a key role in the earlyatmosphere formation resulting in the reduction of $\mathrm{CO}_{2}$ concentration and therebyelevating the oxygen concentration [29]. Moreover, cyanobacteria are still considered to have a major role towards $20-30 \%$ of earth's primary photosynthetic activity as among the different photosynthetic organisms[30].The literature indicated that the enzyme $\mathrm{RuBisCOis} \mathrm{primarily} \mathrm{responsible} \mathrm{for} \mathrm{the}$ utilization of carbon in cyanobacteria, and also catalyzes the same reaction similar to algae for the CBB cycle [31].To achieve $\mathrm{CCM}$, the Cyanobacteria primarily rely on carboxysomes. However, cyanobacteria are reported to be more efficient towards atmospheric carbon fixation due to the presence of a relatively simpler structure in comparison to the algae[32]. In addition to that, the biomass yield for cyanobacteria is also lower as compared to that of algae.Accordingly, cyanobacteria have been reported to be harnessed more frequently for inorganic carbon fixation due to the presence of relatively simpler genetic make-up which can be genetically improved using various genetic engineering techniques for better biomass yield and RuBisCO's $\mathrm{CO}_{2}$ affinityincreased RuBisCO's $\quad \mathrm{CO}_{2}$ affinityand production of useful [33].Previously reported literature also summarized and reported recent advances in the metabolic engineering of cyanobacteria, includingthe production of ethanol, isobutanol, and isoprene[34].

\subsection{Genetically \\ Saccharomyces cerevisiae}

modified

Previously conducted studies reported that Saccharomyces cerevisiae has been relatively less harnessed as a potential mitigative measure for stratospheric $\mathrm{CO}_{2}$ 
emission as compared E. coli. The heterologous expression ofprokaryotic RuBisCO from Thiobacillus denitrificans and PRK fromSpinacia oleracea were also demonstrated in S. Cerevisiae [35].The improved production of malic acid using Saccharomyces cerevisiae by engineering the pathway of $\mathrm{CO}_{2}$ fixation via carboxylation of pyruvate is another notable example. Engineered S. cerevisiae strainhas been reported to produce malate at a titer of up to $59 \mathrm{~g} / \mathrm{L}$, with a malate yield of $0.42 \mathrm{~mole} / \mathrm{mole}$ glucose[36].

\subsection{Protein engineering for enhanced biological CCU}

Protein engineering is an important aspect of genetic engineering and also contributes enormously towards the advancement of biological $\mathrm{CCU}$ as indicated in the earlier section. A wide spectrum of enzymes or proteins has not been evolved or designed to be applied for industrial applications. However, those properties can be customized by the application of a wide spectrum of state-of-the-art protein engineering approaches like rational designing, directed evolution, etc. A wide spectrum of properties like enzymatic activity, specificity, selectivity, thermostability, tolerance to organic solvents, and inhibitors are a few properties that can be enhanced using protein engineering [37].

\subsection{RuBisCO and RuBisCO activase}

The use of engineering tools to improve the selectivity of RuBisCO has been practiced widely[38]. Application of sitedirected mutagenesis on $\mathrm{RuBisCO}$ from green alga $C$. reinhardtii has resulted in the modification on a particular domain which in turn has resulted in the retrogressed $\mathrm{CO}_{2}$ selectivity and thereby decreased $\mathrm{CO}_{2}$ utilization efficiency [39]. Accordingly, this study summarizes the widely accepted hypothesis of the selectivity of the RuBisCo through complex interaction among various amino acid residues apart from their active site. Accordingly, the research niche has beenchanneled toward applying directed evolution to improve the catalytic efficiencyof RuBisCO[40].

\subsection{Bioelectrochemical processes for carbon capture andutilization (CCU)}

The exhaustion of fossil fuels due to various anthropogenic activities has, in turn,led to their immense shortage, and accordingly, their priceis expected to rise exponentially. To circumvent such critical issues, renewable energy sources for 
energy procreation have received significant research attention in the past few decades[1]. One of the widely adopted routes for such development is the conversion of $\mathrm{CO}_{2}$ into such compounds having the potential to store energy. The adoption of such practices will not only promote the replacement of fossil fuel but will also promote and contribute towards attaining overall sustainability. Methane is one such universally recognized compound as a promising alternative that can store energy adopting various chemical routes[41]. Methane is being generated through the anaerobic respiration pathway of various anaerobic microbes. The literature indicated that methane can be harnessed for generating energy which in turn can be used for the genesis of electricity. Additionally, methane could also be used as the precursor for the generation of biodiesel and related products[42]. Accordingly, the route of methane procreation involves the utilization of $\mathrm{CO}_{2}$ for the subsequent conversion into a clean source of energy. There are two predominant pathways of methane genesis namely biotic and abiotic. The biotic route of methanogenesis involves microbial interference whereas the abiogenic route involves the thermal fissure of kerogen. It has been reported that methane production through the biogenic route is widely available. More than $20 \%$ of the total reserve of natural gas is reported to be produced by microbes[43].The potential of the electromethanogenesis process has been investigated globally. The potential of microbes to generatemethane from $\mathrm{CO}_{2}$ reduction via an electrode, which is used asa direct electron donor, has been earlier illuminated in the last few decades[44]. The production of methane has been observed with a cathode potential of $-0.7 \mathrm{~V}$ against $\mathrm{Ag} / \mathrm{AgCl}$ (equivalent to -0.5against standard hydrogen electrode (SHE). At a potential difference of $-1 \mathrm{~V}, 96 \%$ of current has been reportedto be captured into methane. The obtained currentdensities and the small amounts of abiotic hydrogen generationindicated that methane was directly produced from current, andnot from hydrogen gas. Alternatively, it was claimed that a smallamount of methane was directly generated via accepting electronsfrom the electrode, while the remaining portion was biologically generated byhydrogenophilic methanogenesis, consuming abiotic $\mathrm{H}_{2}$ which was generatedfrom the reduction of water molecules[45].Similar results $(-0.2 \mathrm{~V}$ against the SHE) were achieved in other literature reports. The anodic compartment of a dual-chambermethanegenerating microbial electrolysis cell (MEC) fed with acetate, as the main source of carbon, inthe anaerobic medium. The 
cathodic segment was continuously fed with a $\mathrm{CO}_{2}$ and $\mathrm{N}_{2}$ gas mixture for $\mathrm{pH}$ adjustment and carbonate supply. The obtained results indicated $94 \%$ removal of acetate at the anode chamber via anaerobic oxidation with a columbic efficiency of more than $90 \%$. The obtained electric power was mainly recovered in the form of methane[46]. In addition to that, the literature also indicated that activated sludge can also be a potential substrate for methane procreation using $\mathrm{CO}_{2}$ by various

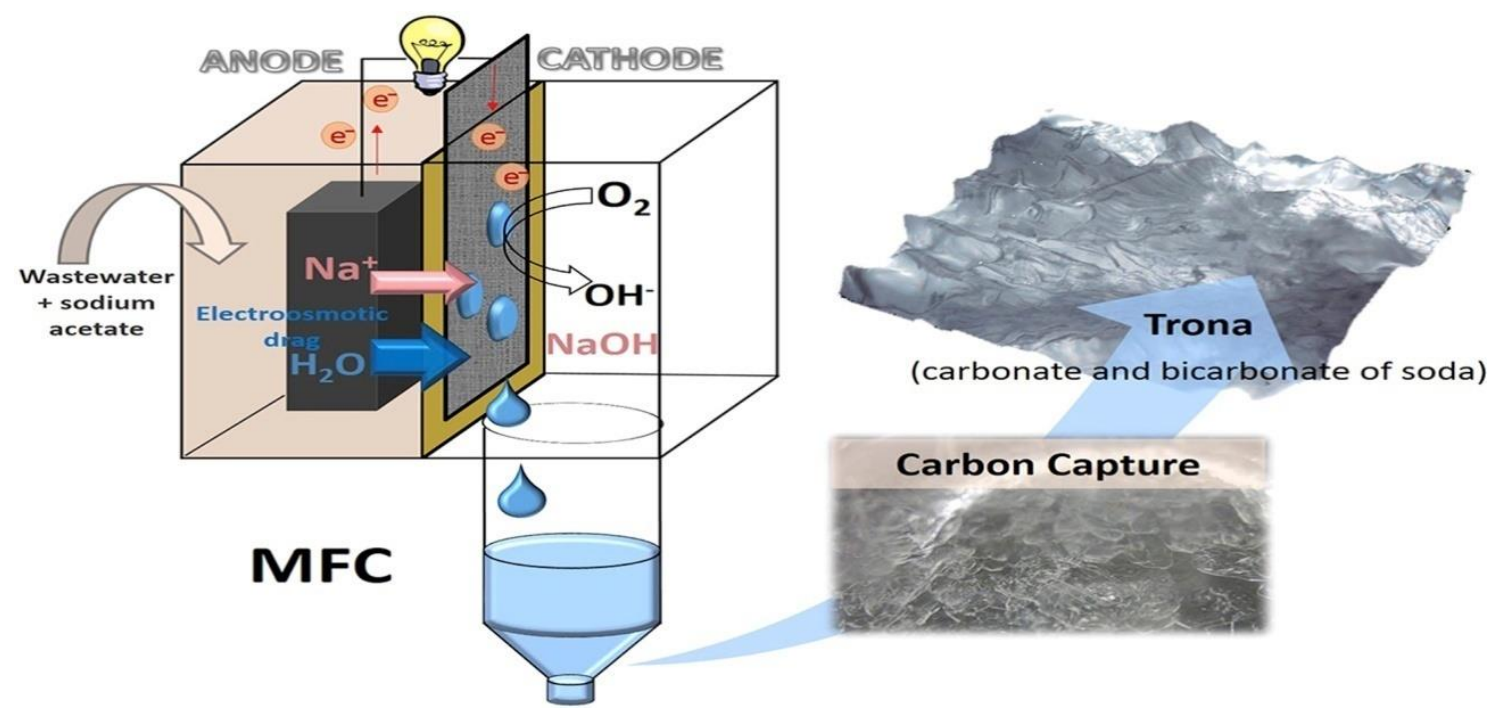

methanogens via an anaerobic route. The production of methane was reported to increase by 70 -fold via dynamic methanogens after 72 hours in the presence of $\mathrm{CO}_{2}$ and $\mathrm{H}_{2}$. The electrochemical conversion Bioelectrochemical systems (BESs), including microbial fuel cells (MFCs), microbial fuel cells (MECs) are reported to be the most promising modes for renewable energy procreation[47].

Figure 2A typical representation of electrolysis cell.

The MFCs are reported to generate bioelectricity using organic wastewater as the feedstock using anodic electrophilic bacteria, whereas MECs mimicphotosynthesis, by electrosynthesizingthe value-added chemicals using $\mathrm{CO}_{2}$ via the cathodic growth of microorganisms as electrocatalysts [48].The MECs are reported to be more superior to MFCs in context to $\mathrm{CO}_{2}$ capturing potential and thereby promotingoverall environmental security. This to electric storage in the form of valuable products, the dependence on nonrenewable energy sources will also decrease[1]. Accordingly, the MECs have grabbed significant research attention in the last few decades, as a novel tool for fuel generation like acetate, formate,hydrogen, or alcohols [45]. 


\subsection{Bio-based products from $\mathrm{CO}_{2}$}

The wide spectrum of $\mathrm{CO}_{2}$ utilizing microorganisms has been studied. The ability to genetically modify microorganisms and the use of protein engineering to tailor enzymatic/proteinproperties have vastly expanded the repertoire of biobasedproducts that can be synthesized directly from $\mathrm{CO}_{2}$ which has been listed in Table-1.

Table 1Representative bio-based products derived from $\mathrm{CO}_{2}$.

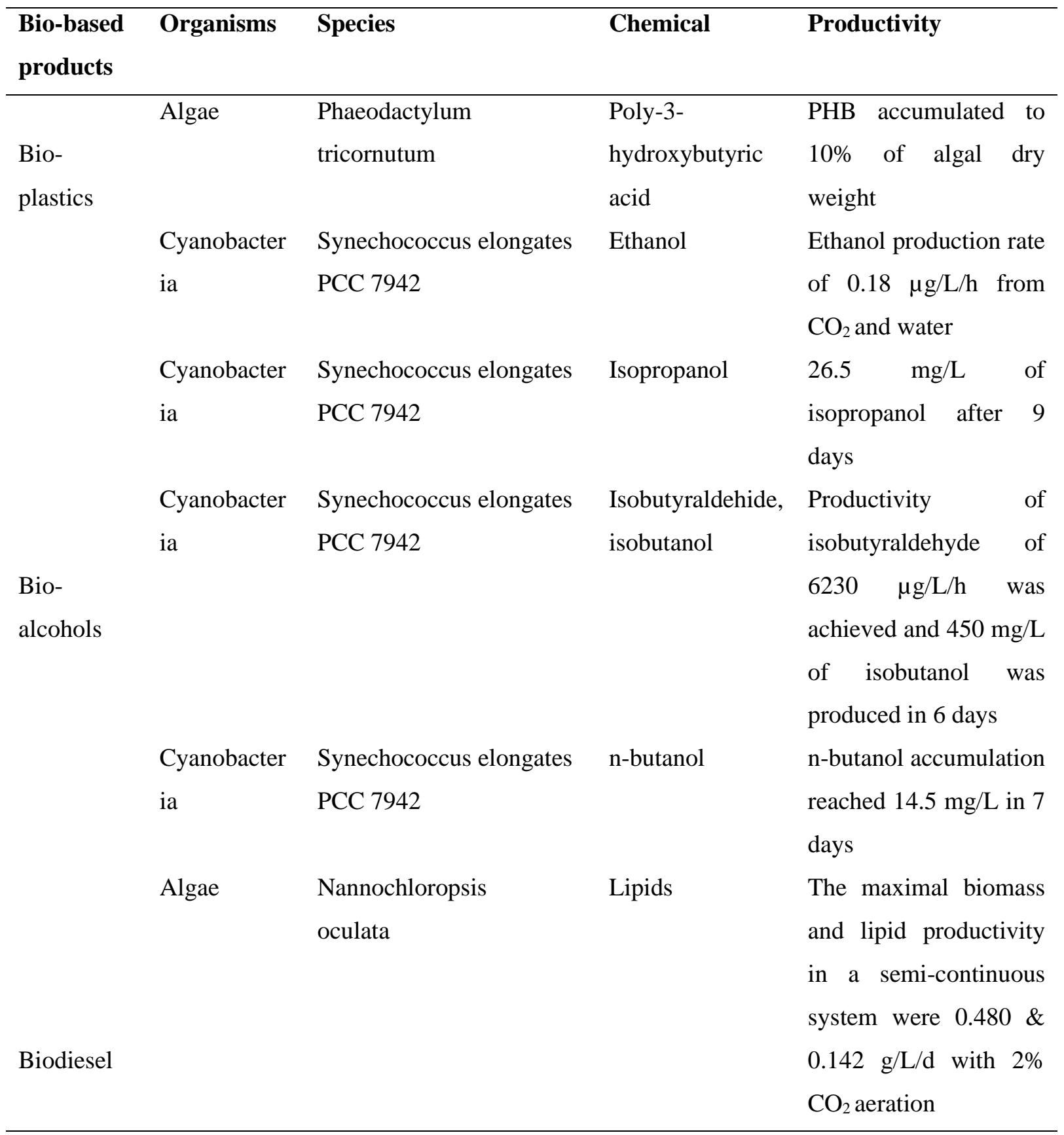




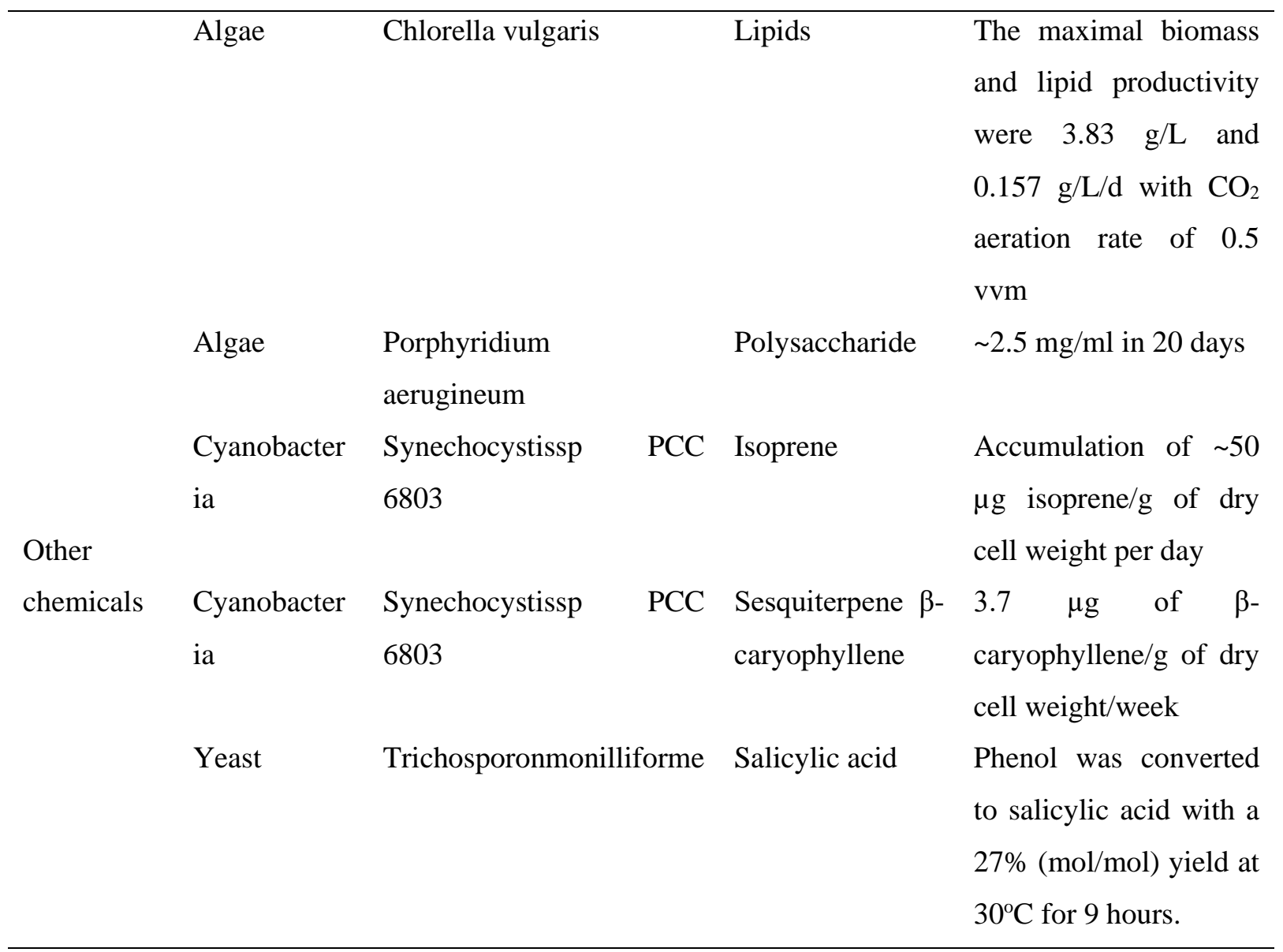

\section{Challenges}

The literature indicated that the industrial cultivation of algae is mainly carried out in open ponds, raceways, or photobioreactors[49].Although, the open ponds for the cultivation of algae have relative ease in their approach, however, there are certain limitations,such as larger land requirement, high cultivation cost, more contamination probability, and lower productivity[50].To circumvent such issues, the use of closed system cultivation using photobioreactor has received significant research attention. The alleviation of the global $\mathrm{CO}_{2}$ reserve represents concurrent global opportunityand thereby helps to attain better and sustainable strategies related to the environment and energy utilization. Such strategies include various environmental-friendly processes linked with $\mathrm{CO}_{2}$ reductions, the generation of industrially value-added chemicalsfrom $\mathrm{CO}_{2}$, and $\mathrm{CO}_{2}$ recycling techniques integrated with sustainableenergy. MES technology has currently been considered as one of the mostpotent approaches to convert $\mathrm{CO}_{2}$ into valuable chemicals. Accordingly, in context to this, microalgae 
have been counted among the most 4. Future prospects and conclusion productive biologicalplatforms for carbon fixation and biomass production.Theintroduction of microalgae in the biological carbon emission mitigationprocess is associated with dual benefits, where $\mathrm{CO}_{2}$ could be directlysupplemented towards the growth of microalgae growth and indirectly employedin extraction and transesterification processes. In addition to that, the harvested microalgal cells have also the potential to be utilized for the generation of renewable energy, food products, value-added chemicals, nutrients, and more.Recent advances in the field of bioprocess engineering of algae havebeen fostered in the past few decades, both in the perspective of scope and diversity. Ahuge advancementhas been achieved inthe various spheres of large-scale algal cultivation, right from $\mathrm{CO}_{2}$ supply to product extraction. In addition to that, it is noteworthy that, life cycle analysis of biodiesel production using algae as the feedstock material using the commercially available data [51].

Table 2The 24 Principles of Green Engineering and Green Chemistry: "IMPROVEMENTS PRODUCTIVELY".

\section{Principles of Green}

Biological CCU

Chemistry* 
P Prevent wastes Recyclable bio-wastes

$\mathrm{R}$ Renewable materials Light/ $\mathrm{H}_{2}$ as an energy source and $\mathrm{CO}_{2} /$ flue gas as carbon source

O Omit derivatization steps $\mathrm{CO}_{2}$ converted via integrated biochemical pathways

D Degradable chemical Biodegradable products products

U Use safe synthetic Use of non-pathogenic organisms methods

C Catalytic reagents Specialized enzymes, micro-compartments, or organelles

$\mathrm{T}$ Temperature, pressure Mild cultivation conditions ambient

I In-process monitoring Process control for bioreactors or fermenters is available

V Very few auxiliary Other non-carbon nutrients derived from biomass substances

E E-factor, maximize feed Yield optimization via strain selection, genetic engineering, in product and synthetic biology

L Low toxicity of chemical Biocompatible products products

Y Yes it's safe Generally safe. Cautions in large-scale $\mathrm{H}_{2} / \mathrm{O}_{2} /$ syngas utilization

\begin{tabular}{|c|c|c|}
\hline & $\begin{array}{l}\text { Principles of Green } \\
\text { Engineering* }\end{array}$ & Challenges of applying biological $\mathrm{CCU}$ \\
\hline $\mathrm{I}$ & $\begin{array}{l}\text { Inherently non-hazardous } \\
\text { and safe }\end{array}$ & $\begin{array}{l}\text { The use } \mathrm{H}_{2} / \mathrm{O}_{2} / \text { syngas presents explosion safety challenges } \\
\text { to large-scale production }\end{array}$ \\
\hline M & $\begin{array}{l}\text { Minimize material } \\
\text { diversity }\end{array}$ & Less of a biological problem \\
\hline $\mathrm{P}$ & $\begin{array}{l}\text { Prevention instead of } \\
\text { treatment }\end{array}$ & Bio-wastes are inevitable in fermentation \\
\hline $\mathrm{R}$ & $\begin{array}{l}\text { Renewable material and } \\
\text { energy inputs }\end{array}$ & $\begin{array}{l}\text { Concentration, composition, temperature, and pressure of } \\
\mathrm{CO}_{2} \text { sources have a direct impact on organismal growth and } \\
\text { productivity. The same applies to energy sources (Example- } \\
\text { Light intensity and wavelength etc.) }\end{array}$ \\
\hline $\mathrm{O}$ & Output-led design & The design of a biological system is not trivial and requires \\
\hline
\end{tabular}


sound knowledge at both the molecular and system level.

The robust genetic tool is lacking for modification of some organisms

V Very simple

E Efficient use of mass, energy, space, and time

M Meet the need

E Easy to separate by design

$\mathrm{N}$ Networks for exchange of Less of a biological problem local mass and energy

$\mathrm{T}$ Test the life cycle of the design

S Sustainability throughout Less of a biological problem the product life cycle integrated, and regulated can be costly and energy-intensive.

Less of a biological problem in product separation.

Less of a biological problem

The biological system is inherently complex, highly

Energy and carbon source are channeled into cell growth and biomass accumulation, instead of chemical production. Low productivity is an issue. The biological membrane could be a barrier to mass/energy transfer. Some enzymes display promiscuous activities (moonlighting). Maintaining strict anoxia for anaerobic cultivation, sparging, and cell stirring

Most organisms or enzymes are not tolerant to solvents used

Biological CCU is not likely to be a standalone technology and accordingly couldpotentially be coupled to other wellestablished chemical processes suchas gasification and water gas shift (WGS) reaction etc. Various biomass feedstocks likewood and straw contain a huge portion of indigestible chunksthat cannot be degraded and fermented by microorganisms.Accordingly, an excellent alternativein this regard would be biomass gasification, partial oxidation of carbonaceouscompounds into a mixture of $\mathrm{CO}, \mathrm{CO}_{2}$, and $\mathrm{H}_{2}$.Additionally, the technical aspects described in this review, the advancement of biological $\mathrm{CCU}$ is highly dependent on other crucialfactors such as R\&D funding commitment to reducingcarbon footprint, governmental policies (e.g., carbon tax,cap-and-trade system), and incentives for CCU (e.g., $a$ tax credit forrenewable energy and for developing/deploying energyefficientequipment/technologies). Often, 
these factors trigger much discussionand debate, at both national and international levels. Accordingly, we conclude by remarking that scaling-up and industrial implementation of biological and bioelectrochemical utilization ofCO $_{2}$ can only be realized by close collaboration between scientists and engineers.

\section{References:}

1. Roy, R., Ray, S., 2019. Effect of various pretreatments on energy recovery from waste biomass. Energy Sources, Part A: Recovery, Utilization, and Environmental Effects, 1-13.

2. Wilberforce, T., Olabi, A. G., Sayed, E. T., Elsaid, K., Abdelkareem, M. A. 2021. Progress in carbon capture technologies. Science of The Total Environment, 761, 143203.

3. Darensbourg, DJ., 2010. Chemistry of carbon dioxide relevant to its utilization: apersonal perspective. Inorganic Chemistry, 49, 1076510780.

4. Field, CB., Behrenfeld, MJ., Randerson JT., Falkowski P., 1998. Primary productionof the biosphere: integrating terrestrial and oceanic components. Science, 281, 237-240.
5. Roy, R., Ray, S., 2020. Development of a non-linear model for prediction of higher heating value from the proximate composition of lignocellulosic biomass. Energy Sources, Part A: Recovery, Utilization, and Environmental Effects, 1-14.

6. Roy, R., Ray, S., 2021. Upgradation of an Agro-residue by Acid Pretreatment into a Solid Fuel with Improved Energy Recovery Potential: An Optimization Study. Arabian Journal for Science and Engineering, 1-13.

7. Sabri, M. A., Al Jitan, S., Bahamon, D., Vega, L. F., Palmisano, G., 2021. Current and future perspectives on catalyticbased integrated carbon capture and utilization. Science of The Total Environment, 790, 148081.

8. Rossi, F., Olguín, E.J., Diels, L., De Philippis, R., 2015. Microbial fixation of $\mathrm{CO}_{2}$ in water bodies and in drylands to combat climate change, soil loss and desertification. New Biotechnology, 32, 109-120.

9. Roy, R., Debnath, D., Ray, S., 2021. Comprehensive Assessment of Various Lignocellulosic Biomasses for Energy Recovery in a Hybrid Energy System. Arabian 
Journal for Science and Engineering, 1-14.

10. Nasir, R., Ahmad, S. R., Shahid, M., 2021. Emission reduction energy model of Punjab: A case study. Journal of Cleaner Production, 329, 129755.

11. Zahedi, R., Ahmadi, A., Dashti, R., 2021. Energy, exergy, exergoeconomic and exergoenvironmental analysis and optimization of quadruple combined solar, biogas, SRC and ORC cycles with methane system. Renewable and Sustainable Energy Reviews, 150, 111420.

12. Rosso, D., Stenstrom, M.K., 2008. The carbon-sequestration potential of municipal wastewater treatment. Chemosphere, 70, 1468-1475.

13. Fernandez, E., Galvan, A., 2007. Inorganic nitrogen assimilation in Chlamydomonas. Journal of experimental botany, 58, 22792287.

14. Alami, A. H., Alasad, S., Ali, M., Alshamsi, M. 2021. Investigating algae for $\mathrm{CO}_{2}$ capture and accumulation and simultaneous production of biomass for biodiesel production. Science of The Total Environment, 759, 143529.

15. Hassaan, M. A., Hosny, S. 2018. Green synthesis of $\mathrm{Ag}$ and $\mathrm{Au}$ nanoparticles from micro and macro algae-review. International Journal of Atmospheric and Oceanic Sciences, 2, 10-22.

16. Chen, P., Min, M., Chen, Y., Wang, L., Li, Y., Chen, Q., Wang, Q.,Li, Y., Chen, Q., Ruan, R. 2010. Review of biological and engineering aspects of algae to fuels approach. International Journal of Agricultural and Biological Engineering, 2, 1-30.

17. Shi, LX., Theg, SM., 2013. The chloroplast protein import system: from algae to trees. Biochimica et Biophysica Acta, 1833, 314-331.

18. Atomi, H., 2002. Microbial enzymes involved in carbon dioxide fixation. Journal of Bioscience and Bioengineering, 94, 497-505.

19. Cai, Z., Liu, G., Zhang, J., and Li, Y., 2014. Development of an activity-directed selection system enabled significant improvement of the carboxylation efficiency of Rubisco. Protein \& cell, 5, 552562.

20. Parry, MA., Andralojc, PJ., Mitchell, RA., Madgwick, PJ., Keys, AJ., 2003. Manipulationof Rubisco: the amount, activity, function and regulation. Journalof 
Experimental Botany, 54, 13211333.

21. Meyer, M., Griffiths, H., 2013.

Origins and diversity of eukaryotic $\mathrm{CO}_{2}$-concentrating mechanisms: lessons for the future. Journal of Experimental Botany, 64, 769-786.

22. Walker, TL., Collet, C., Purton, S., 2005. Algal transgenics in the genomic era. Journal of Phycology, 41, 1077-1093.

23. Lü, J., Sheahan, C., Fu, P., 2011. Metabolic engineering of algae for fourth generation biofuels production. Energy \& Environmental Science, 4, 24512466.

24. Yadav, G., Sen, R. 2017. Microalgal green refinery concept for biosequestration of carbondioxide vis-à-vis wastewater remediation and bioenergy production: Recent technological advances in climate research. Journal of $\mathrm{CO}_{2}$ Utilization, 17, 188-206.

25. Mussgnug, JH., Thomas-Hall, S., Rupprecht, J., Foo, A., Klassen, V., et al. 2007.Engineering photosynthetic light capture: impacts on improved solar energy tobiomass conversion. Plant Biotechnology Journal, 5, 802-814.
26. Gregory, JA., Li, F., Tomosada, LM., Cox, CJ., Topol, AB., Vinetz, JM., Mayfield, S. 2012. Algaeproduced Pfs 25 elicits antibodies that inhibit malaria transmission. PloS one, 7, e37179.

27. Specht, E., Miyake-Stoner, S., Mayfield, S., 2010. Micro-algae come of age as a platform for recombinant protein production. Biotechnology Letters 32: 13731383.

28. Cardona, T., 2016. Origin of bacteriochlorophyll a and the early diversification of photosynthesis. PLoS One, 11, e0151250.

29. Kasting, JF., Siefert, JL., 2002 Life and the evolution of Earth's atmosphere. Science, 296, 10661068.

30. Pisciotta, JM., Zou, Y, Baskakov, IV., 2010, Light-dependent electrogenic activity of cyanobacteria. PLoS One, 5, e10821.

31. Moroney, JV, Jungnick, N., DiMario, RJ, Longstreth, DJ, 2013, Photorespiration and carbon concentrating mechanisms: two adaptations to high $\mathrm{O}_{2}$, low $\mathrm{CO}_{2}$ conditions. Photosynthesis research, 117, 121-131.

32. Oliver, JW, Machado IM, Yoneda, H., Atsumi, S., 2014, 
Combinatorial optimization of

cyanobacterial 2,3-butanediol

production. Metabolic Engineering

22: $76-82$.

33. Rabinovitch-Deere, C.A., Oliver, JW., Rodriguez, GM., Atsumi, S., 2013, Synthetic biology and metabolic engineering approaches to produce biofuels. Chemical Review, 113, 4611-4632.

34. Quintana, N., Van der Kooy, F., Van de Rhee, MD., Voshol, GP., Verpoorte, R., 2011, Renewable energy from Cyanobacteria: energy production optimization by metabolic pathway engineering. Applied Microbiology and Biotechnology 91, 471-490.

35. Guadalupe-Medina, V., Wisselink, HW., Luttik, MA., deHulster, E., Daran, JM, et al. 2013, Carbon dioxide fixation by Calvin-Cycle enzymes improves ethanol yield in yeast. Biotechnology for Biofuels and Bioproducts 6,1-12.

36. Zelle, RM., Harrison, JC., Pronk, JT., van Maris, AJ., 2011, Anaplerotic role for cytosolic malic enzyme in engineered Saccharomyces cerevisiae strains. Applied and Environmental Microbiology, 77, 732-738.

37. Singh, RK., Tiwari, MK., Singh, R., Lee, JK., 2013. From protein engineering to immobilization: promising strategies for the upgrade of industrial enzymes. International journal of molecular sciences, 14, 1232-1277.

38. Drummond, ML., Cundari, TR., Wilson, AK., 2012, Protein-based carbon capture: progress and potential. Greenhouse Gases: Science and Technology, 2, 223238.

39. Karkehabadi, S., Satagopan, S., Taylor, TC., Spreitzer, RJ., Andersson, I., 2007,Structural analysis of altered large-subunit loop-6/carboxy-

terminusinteractions that influence catalytic efficiency and $\mathrm{CO}_{2} / \mathrm{O}_{2}$ specificity of ribulose-1,5bisphosphatecarboxylase/oxygenas e. Biochemistry, 46, 11080-11089.

40. Mueller-Cajar, O., Whitney, SM., 2008 Directing the evolution of Rubisco and Rubisco activase: first impressions of a new tool for photosynthesis research. Photosynthesis Research, 98, 667675.

41. Huang, CH., Tan, CS., 2014. A review: $\mathrm{CO}_{2}$ utilization. Aerosol and Air Quality Research, 14, 480499.

42. Chandra, R., Takeuchi, H., Hasegawa, T., 2012. Methane 
production from lignocellulosic agricultural crop wastes: a review in context to second generation of biofuel production. Renewable \& Sustainable Energy Reviews, 16, 1462-1476.

43. Sato, K., Kawaguchi, H., Kobayashi, H., 2013, Bioelectrochemical conversion of carbon dioxide to methane in geological storage reservoirs. Energy Conversionand Management, 66, 343-350.

44. Cheng, S., Xing, D., Call, DF., Logan, BE., 2009, Direct biological conversion of electrical current into methane by electromethanogenesis.

Environmental Science and Technology, 43, 3953-3958.

45. Villano, M., Aulenta, F., Ciucci, C., Ferri, T., Giuliano, A., Majone, M., 2010,Bioelectrochemical reduction of $\mathrm{CO}_{2}$ to $\mathrm{CH}_{4}$ via direct and indirect extracellular electron transfer by a hydrogenophilic methanogenic culture. Bioresource Technology, 101, 3085-3090.

46. Villano, M., Scardala, S., Aulenta, F., Majone, M., 2013, Carbon and nitrogen removal and enhanced methane production in a microbial electrolysis cell. Bioresource Technology, 130, 366-371.
47. ElMekawy, A., Hegab, H.M., Dominguez-Benetton, X., Pant, D., 2013, Internal resistance of microfluidic microbial fuel cell: challenges and potential opportunities. Bioresource Technology, 142, 672-682.

48. Rabaey, K., Rozendal, R.A., 2010, Microbial electrosynthesis revisiting the electrical route for microbial production. Nature Reviews Microbiology, 8, 706716.

49. Wijffels, RH, Barbosa, MJ., 2010, An outlook on microalgal biofuels. Science, 329,796-799.

50. Ketheesan, B., Nirmalakhandan, N., 2012, Feasibility of microalgal cultivation in a pilot-scale airliftdriven raceway reactor. Bioresource Technology, 108, 196202.

51. Passell, H., Dhaliwal, H., Reno, M., Wu, B., Ben Amotz, A., et al., 2013, Algae biodiesel life cycle assessment using current commercial data. Journal of Environmental Management, 129, 103-111. 